\title{
Fe Reichelt: Aufbau der Mitte. Morgenübungen und Umkehrung der Atmung
}

Brandes und Apsel, 2018, Frankfurt/M., 8o Seiten, 9,90€(D)

Vo

or einigen Jahren hatte ich Gelegenheit, die heute 92-jährige Autorin persönlich kennenzulernen und mit ihr, anlässlich einer Mitgliederversammlung des Berufsverbandes der Tanztherapeutinnen Deutschlands (BTD), den Frühstückstisch zu teilen. Sie trug einen pinkfarbenen Pullover und ein ebenso einladendes, strahlendes Lächeln. Sie war damals schon in den Achtzigern, aber ihre Gesellschaft fühlte sich eher an wie die eines quirligen, lebensfrohen Mädchens. Sie sprühte vor Ideen, nahm voller Interesse an den berufspolitischen Themen der Tagung teil, wenn auch mancher Konflikt ihr sehr unwichtig erschien, und ich erinnere mich gut daran, wie heilsam und klärend ich es fand, die Dinge aus ihrem aufs Wesentliche bezogenen - Blickwinkel zu betrachten.

Sie war noch nicht lange von einer Erkrankung genesen, und als wir darauf zu sprechen kamen, was ihr so schnell und effektiv wieder auf die Beine geholfen hatte, berichtete sie mir ausgiebig von ihren Morgenübungen, die auch Gegenstand des vorliegenden Buches sind. Sie zeigte mir sogar ihren Terminkalender, in den sie die Durchführung der Übungen akribisch eingetragen hatte, und erklärte dazu, wie wichtig es für den Erhalt ihrer Lebensenergie sei, diese regelmäßig durchzuführen, und dass sie sich dabei nur selten eine Pause leistete. Auch die Bedeutung der Atmung und die Umkehrung der Atmung, die sie mit den Morgenübungen verknüpft, machte sie mir deutlich: Als Nichts mehr ging, sei das Atmen der entscheidende Faktor gewesen, der sie wieder auf die Beine gebracht habe. Damit nehme alles seinen Anfang und sein Ende.

Vor diesem Hintergrund meines persönlichen Erlebens der Autorin habe ich mit großem
Interesse ihr jüngstes Werk „Aufbau der Mitte" gelesen. Auch dieses Buch ist - wie all seine Vorgänger im Brandes und Apsel Verlag erschienen. Es hat 80 Seiten, von denen 50 den Morgenübungen in Verbindung mit dem Atem gewidmet sind. So viel zu dem, was als erstes ins Auge fällt und was dem Buch mit den Worten Laotse's als Motto vorangestellt ist: „Das Sichtbare bildet die Form eines Werkes, das Nicht-Sichtbare macht seinen Wert aus."

Fe Reichelt will ihr neues Buch ausdrücklich als Ergänzung zu ihrem 2005 erschienen Werk „Tanz der Wandlungen“ verstanden wissen. Man muss aber der Ehrlichkeit halber dazu sagen: Wer diesen Vorgänger kennt, findet auch schon fast die Hälfte der Übungen dort beschrieben. Es scheint mir die Essenz eines langen Tänzerinnen-Lebens zu sein, die hier noch einmal zusammengefasst niedergeschrieben werden wollte.

Nichtsdestotrotz bleibt es eine Herausforderung und was für Fortgeschrittene, den größtenteils sehr dynamischen Übungsfolgen aus der rein textlichen Beschreibung wirklich zu folgen, auch wenn die Bilder (dieselben wie im Tanz der Wandlungen) als ergänzende Beschreibungen zum Verständnis beitragen sollen. Wir haben es als drei Tanztherapeutinnen gemeinsam versucht (eine liest und zwei machen die beschriebenen Übungen, können also auch noch gegenseitig abschauen...), und es ist uns in vier von fünf Versuchen nicht gelungen.

Vielleicht sieht man daran auch, wie sehr wir mittlerweile daran gewöhnt sind, Video- 
Anleitungen als Beschreibungsmittel zu nutzen. Könnte man die Bewegungsabläufe in ihrer Dynamik einmal im ganzen Ablauf sehen, wäre es vielleicht ganz einfach zu begreifen und bestimmt ein Gewinn. Und obwohl ich natürlich weiß, dass es eine unverschämte Zumutung ist, möchte ich hier vorschlagen, ein Youtube-Video davon zu machen.

Das eigentliche Herzstück dieses kleinen Büchleins - vielleicht das, was seinen „unsichtbaren“ Wert ausmacht, obwohl es weder im Titel noch im Untertitel als Inhalt erscheint ist die Biographie der Fe Reichelt: schnörkellos und doch bewegend, ein ganz besonderes Stück Zeitgeschichte, Lebensweg einer spät berufenen Tänzerin, die dafür nicht schon mit 30 die Bühne verlassen hat, sondern hochbetagt noch bewegende Themen fand, die sie tänzerisch ausdrucksstark darstellte. Die Geschichte einer leidenschaftlichen und sanften
Kämpferin, die Generationen von TanztherapeutInnen ausgebildet, geprägt und anhaltend inspiriert hat.

Der Verlagsfreund Volkhardt Brandes hat die Frage aufgeworfen: Was macht den Menschen aus, der 1925 in China geboren, 1936 nach Deutschland zurückgekehrt und 1949 als Meisterschülerin bei Mary Wigman zum Ausdruckstanz gekommen ist? Die von Ost nach West von München über Frankfurt nach Berlin gezogen ist und überall ihre Spuren hinterlassen hat?

Es lohnt sich, diese 27-seitige Biographie zu lesen. Als Lebensgeschichte einer Frau, der „nur zu tanzen nicht genügt hat“, sondern die zeitlebens versucht hat, tiefer in das Geheimnis des Tanzes vorzudringen und dabei lang gewandelt und weit gekommen ist.

\section{Marion Reuter}

DOI 10.2378/ktb2020.arto8d 